\title{
Research Projects Writing Skills and other Challenges Faced by Master and PhD Students at the Open University of Tanzania
}

\author{
Dr. Joseph Magali (PhD) \\ The Open University of Tanzania \\ josephmagali@yahoo.com
}

\begin{abstract}
Received: Feb. 21, 2019 Accepted: March 20, 2019 Published: April 16, 2019
doi:10.5296/ijssr.v7i1.14668 URL: http://dx.doi.org/10.5296/ijssr.v7i1.14668
\end{abstract}

\begin{abstract}
Every Master and $\mathrm{PhD}$ student at the Open University of Tanzania (OUT) has to make a research project as one of the requirements for completing their degree programmes. However, most students at the OUT face challenges in their research writing process due to lack of the research writing skills. This paper discusses the research writing skills and other challenges which the Master and PhD students face at the OUT. The challenges were learned from the researcher's personal experiences of five years in supervising and training students on research methodology course for Master and $\mathrm{PhD}$ students at the OUT. Foremost, this paper presents the sections of the research proposal and research report which are mostly problematic to students and the author provides the suggestions on improvements. These sections include background information, the problem statement, research objectives, theoretical and empirical literature review, the research gap, research design, approach, strategy and philosophy, variables and measurements, data analysis, results and interpretation and conclusion and recommendations. Secondly, the paper also discusses other challenges which hinder students' theses and dissertations timely completion at the OUT which include insufficient research orientation, lack of reading culture lack of facilitation methods' integration for research course trainers, lack of awareness on students-supervisors responsibilities, lack of research completion strategy, low level of English language proficiency and lack of funds and health problems. Finally, the paper presents conclusions and recommendations for improvements.
\end{abstract}

Keywords: Research projects, research writing skills, and students' research writing challenges 


\section{Introduction}

The Open University of Tanzania (OUT) is a full-fledged public institution of higher learning that was established in 1992. It conducts academic programmes leading to awards of certificates, diplomas, undergraduate and postgraduate qualifications through Open and Distance Learning (ODL) delivery system. Since 1999-2018 OUT has admitted a total of 5,196 postgraduate students in postgraduate diploma, master and $\mathrm{PhD}$ programmes (OUT Facts and Figures, 2018).

The requirement for writing a thesis or dissertation before completion of Master or $\mathrm{PhD}$ degree is set at the OUT and other higher learning institutions so that the students may improve among others, the research information searching, organizing, evaluation, and self expression skills (Whitaker, 2009). Furthermore, Vijayakumar and Vijayakumar (2007) argue that $\mathrm{PhD}$ thesis results should make an original contribution to the knowledge while the conclusions and recommendations of these studies should contribute to the economic and social improvement of the society's livelihood. Smith et al. (2008) declare that while the Master dissertations make students to transform the theoretical aspect in a practical way; the $\mathrm{PhD}$ thesis is designed to make a student to be more theoretical equipped with enough argumentative skills.

However, in order to produce a good research report, a postgraduate student needs a variety of skills such as writing skills, language skills, relationship management skills and other skills (Tichapondwa, 2013; Fareed, Ashraf, \& Bilal, 2016; O’Neill \& Gravois, 2017). Possession of these skills by students is essential because they help students on not only to write the research report on time but they are equally important for maintaining the good relationship with their supervisors (Blicblau et al., 2009).

The empirical literatures assert that students face difficult in writing their dissertations and theses in countries which the language of research writing is English but the students' mother language is different from English (Iftanti, 2016; Fareed et al., 2016; Alfaki, 2015; Shang, 2013). Arguably, in these countries students fail to write and express their ideas confidently using the English language. Apart from the writing skills, Tichapondwa (2013) mentions other challenges which restrict postgraduate students not to accomplish their studies on time. These challenges include: poor relationship between students and supervisors, ethical and malpractice issues (dishonesty and untrustworthiness), supervisor/candidate change, failure to adhere and respect the institutional house style, and differing expectations among supervisors. Phillips and Pugh (2005) add that boredom and frustration also affect PhD students when writing their theses. Thus, this paper is designed to assess the writing skills and other challenges faced by postgraduate students at the OUT, during the process of writing their dissertations and theses.

\section{The Problem Statement}

Despite the standard completion time for Master and $\mathrm{PhD}$ students at the OUT being two and three years respectively, majority of students (more than half) goes beyond the stipulated standard minimum completion time (OUT Graduation Booklet, 2018). Therefore, it is 
obvious that most of the students either lack the required writing skills or face other challenges in the process of writing their dissertation/theses. These challenges which are faced by students, either increase the supervisory burden or instigate conflict between students and supervisors, which ultimately hinder timely completion of students' studies. Therefore, this paper identifies and discusses the writing skills and other challenges which hinder the theses' and dissertations' timely completion for postgraduate students at the OUT.

\section{Methodology}

This paper uses the researcher's experience gained from supervision of more than 50 Master and $15 \mathrm{PhD}$ students from 2014 to 2019 . The author also uses the experience gained from the face to face and online teaching the course on the research methodology to more than 300 postgraduate students. The analysis of information is done by using experience sharing analysis. The analysis is based on research concepts presented by students, in their proposals and research reports compared to the standard on what they were supposed to present. The paper also presents other challenges which inhibit students to complete their research projects on time at the OUT.

\section{The Literature Review}

\subsection{Theoretical Literature Review}

This article uses both social cognitive theory and cognitive-behavioral theory. Akers (2018) asserts that the social cognitive theory describes how person's actions, personality and circumstances are controlled by individual thoughts. When both personal thoughts and the physical environment influence the behaviour, actions, personality and circumstances of an individual, the theory is called social cognitive-behavioral theory. However, the mood disorder may make an individual fail to control his thoughts. Also criticism from other people may influence the thoughts of an individual and make an individual to think beyond his thoughts.

The initial ideas of cognitive theory were originated from Holt and Brown (1931) who theorized that if a person is imitated, then he can learn to imitate others. Miller and Dollard (1941) expanded the imitation theory by asserting that learning of a particular behaviour by an individual depends on the level of motivation. Moreover, the social learning cognitive theory was contributed largely by Albert Bandura who wrote several articles and books to explain what motivates and modifies the personal behaviours. By using the children toy (Bobo) experiment, Bandura established why and when children show destructive behaviors after watching the doll. In 1977, Bandura established the relationship between a person's perceived self-efficacy and behavioral change where he revealed that a person's perceived self-efficacy is a result of performance accomplishments, vicarious experience, verbal persuasion, and physiological states. The social cognitive theory was officially established by Bandura in 1986 by revealing that human behavior is influenced by personal, behavioral and environmental factors. In 2001, Bandura established that watching programmes on TV may influence an individual to acquire and adopt behaviour while in 2011; Bandura extended the application of the social cognitive theory to health and urgent global issues such as environmental conservation. 
The author perceives that social cognitive theory and behavioural theory are correlated with the way students at the OUT carry out their researches because writing of a good research report by the postgraduate students depends on myriad of factors. Indeed, the completion of the research by Master and $\mathrm{PhD}$ students depend on factors that are related with the students themselves, their supervisors and the academic environmental exposure of students. The implication is that, if the students are not motivated to do their researches, neither the supervisors nor the environments can boost the students to complete their theses or dissertations on time. This also is true if students do not possess the required skills because they will not present correctly the research concepts. Therefore, the quality of good research reports depend on the students thoughts (skills), experience in research matters and conducive environments which motivates students to learn and apply the learned skills.

While the previous studies such as Holt and Brown (1931), Miller and Dollard (1941), Bandura $(1977 ; 1986 ; 2001 ; 2011)$ and Akers $(2018)$ have linked the social cognitive theory with education and other fields, to the best of the author knowledge, none of the study has linked this theory with the way the research is carried out, especially for postgraduate students in higher learning institutions. That is why the paper uses this theory as a lens to delineate how the social learning theory may be used to improve the research completion time for postgraduate students at OUT and possibly to other higher learning institutions.

\subsection{Empirical Literature Review}

Due to the research writing problems in universities and higher learning institutions, the literatures disclose various strategies which may be used to improve the writing skills amongst postgraduate students in these institutions. The suggested strategies include writing regularly the journal articles (Iftanti, 2016), use of photography, autophotograhy and music (Pesik, 2010), referring wikipedia when writing the academic assignments (Miller, 2014), blogging daily (Lin et al., 2014), writing regularly in the facebook, using smartphones (Sulisworo et al., 2016) and adequate level of teachers' preparation, teaching and providing students many opportunities to learn the foreign languages (Chokwe, 2013).

Other strategies include building students' competence, motivating them and allocating them the supportive research mentors (Tan, 2007), fostering good relationship between the students and their supervisors (Blicblau et al., 2009), building good perceptions between staff and students on what constitutes the good academic writing (Itua et al., 2014), students to spend adequate time in reading and writing academic texts, journals and referencing materials and using the blended learning (Adas \& Bakir, 2013; Ho, et al., 2015), students' reflections, feedback and writing and revisions of completed and draft assignments (Farrah 2012; McNaught \& Benson, 2015; O’Neill \& Gravois, 2017; Lumpkin, 2018), use of automated essay scoring software (Kellogg, 2008) and use of word processing, spelling checkers, word prediction and speech recognition (MacArthur, 2009).

Other scholars also report that writing dissertations and theses by university students is hindered by low level of English proficiency (Fareed et al., 2016; Sersen, 2011; Alfaki, 2015; Shang, 2013; Nik et al., 2010; Sajid \& Siddiqui, 2015). These scholars therefore propose several strategies which may be used by students to improve their English language 
proficiency. These strategies includes, encouraging students to read more vocabularies, improve their writing practices, training teachers on the best ways of teaching language, improve the examination system's and organizing the writing competitions (Fareed et al., 2016), students' writing and correction of mistakes regularly by teachers (Sersen, 2011), composition writing and correction of spelling mistakes by using dictionaries or spellcheckers (Alfaki, 2015), practicing the peer revision and formation of small students' discussion group (Shang, 2013), teaching students English language (Nik et al., 2010) and use of English language since the primary schools (Sajid \& Siddiqui, 2015).

While the previous papers such as Iftanti (2016), Sulisworo et al. (2016), Miller (2014), Lin et al. (2014) and Chokwe (2013), just to mention a few, describe the skills needed to write a good research articles and provided the suggestions on what to do to improve the writing skills; this paper discusses how the research skills can help the OUT's student to write the good research articles, proposals and research reports. The paper also identifies and discusses other challenges which influence on time completion of theses and dissertations by students at the OUT.

\section{Results and Discussion}

\subsection{Writing Skills Problems in Students'Theses an Dissertations at OUT}

This section presents and discusses the findings which are from the author's experience. The findings are based on the way the postgraduate students at the OUT present the research concepts when writing their theses and dissertations. The author presents only the dissertations' and theses' sections which seem to be the most problematic to students.

\subsubsection{Background Information}

Some scholars call the background information section as an introduction. However, these two terms differ slightly because the background information presents more detailed information than introduction section (Jilcha, 2017). The author has noted that many students write anything they want in the background of the problem. But in facts, the students can't write the section of the background information properly if they have not completed the chapter of the literature review which covers the theoretical and empirical sections. Therefore, the background of the study is the "Summary of the chapter of the Literature Review" (Shay, 2015). Actually the background information should indicate the significance of the study. The students should also present in a narrative way, existence of contradicting results (if any), gaps to fill (both empirical and theoretical), and if there are untested theories or hypotheses on the topic (Bavdekar, 2015). However, the background information is just a summary; therefore, it should not be overloaded by unnecessary information such as many figures and tables (Bavdekar, 2015). The author proposes that the background information, if the font is double spaced, it should not exceed two and half pages.

\subsubsection{The Problem Statement}

Problem statement is the evidence that a certain problem which requires research exists in a particular area (Fischler, n.d). Usually it is not worth to conduct a research, if the research 
will not solve a specific problem. However for students, this is the area which is not understood by most of them. It should be noted that, the research problem consists of two parts; the first part presents the existence of the problem while the second part is the research gap (Fischler, n.d). However, most students present only the second part which is the research gap and forget the first part which requires them to present the problem and its magnitude. The author emphasizes that the problem should be drawn from the area of the research. The students usually present the problem widely focusing the national or international scope without presenting the problem which has been originated from the area of the research. For example, a student may argue that there is a problem of job turnover in his working place but does not present the turnover data say of three or more years to justify that the turnover problem exists in a particular study area.

\subsubsection{Research Objectives}

Most students do not understand what constitute the research objectives. Objectives of the research are questions that the students are required to answer at the end of their studies (Farrugia et al., 2010). In order to answer these questions, the objectives should be SMART (Specific, Measurable, Realistic and Time bound). In addition, many students fail to link between the general and specific objectives. For example if the students' general objective is to assess the factors affecting job turnover, in the specific objective, the students should state those factors. The factors may be written either in the form of groups or individuals. For example, social-cultural factors and monetary payments are group and individual factors which may affect the job turnover in a particular organization respectively. Furthermore, students should note that there is an existing relationship between the objectives, theoretical analysis, conceptual framework, the research gap, variables and measurement and the questionnaire.

\subsubsection{Theoretical Literature Review}

The theoretical literature review comprises of definition of terms, historical literature review, policy review, explanations of the concepts based on objectives and the theoretical framework. The common students' practice is to include these concepts without arguments or systematic flow. Usually the students would like to include everything in this section without explaining why these concepts are important as far as their studies are concerned. For example in the definition of terms, the students are advised to define terms that are only found in the title of the study because the experience show that most students would like to define every term which they think is relevant. In this section, students should also critique the concepts, policies or theories. In the policies, the students should explain if the policies are still valid or there is a policy gap. In the theoretical section, the student should present only few theories which are relevant to their study; probably one or two. However, some supervisors prefer presentation of many theories and then the students are requested to specify the relevant theories for the particular study. In some incidences, Supervisors would like to present only one or two theories that are closely related with the objectives of the study. The author agrees with the later approach, that the students should outline only the theories that will be used in their studies. This is emphasized, because at the end of the study, 
the students should explain how their studies have contributed to the theories, which sometimes becomes difficult to the students; if they have used many theories. While, the theory is the statement which explains the relationship between particular concepts, situations or phenomena (Mouza, 2018); most students fail to present neither the originator nor the statement of the theory. Moreover, most students fail to indicate the theoretical gap and the link between the theoretical gap and their study objectives. The theoretical gap includes the variables of the theory which have not been covered by the previous authors. Furthermore, according to Nakano and Muniz Jr (2018), theoretical gap(s) refers to a missing point in the current knowledge on a subject or any identified information caused by improper discussion of the literature review. However, before presenting the theoretical gap, the students should present the development of the theory. The development of the theory covers the variables introduced to the theory apart from the variables of the principle author(s) of the theory.

\subsubsection{Empirical Literature Review}

While the theoretical literature review presents the statements of the concepts, theory or policy; the empirical literature review presents findings from the previous studies done to assess a particular problem (Kumar, 2011). The students usually present the findings of the particular studies without critiquing them. In the standard research writing, the presentation of the empirical literature review should go hand in hand with critical analysis of the same. Critiques in this context means how the students can find a gap from the previous studies after composing their titles and specific objectives of their studies. Critiquing should include what is missing from the previous studies when students connect with their current studies. Critiquing usually is done based on the sample size, sampling methods, geographical location, objectives and method (s) used for data collection and analysis.

\subsubsection{The Research Gap}

The research gap is derived from the research question which has not been addressed properly from the previous studies (Farooq, 2017). Usually for every study, there should be a gap to be covered. As stated in the previous sections, the gap may be contextually, methodologically, geographically and theoretically. Researchers should explain clearly what gaps will be covered in their studies. Moreover, studies may be conducted to verify the previous studies where weaker methodologies may be replaced with stronger ones. In order to fill the gap, students may wish to increase the sample size or expand their studies into broader coverage to validate the previous studies.

\subsubsection{Research Design, Approach, Strategy and Philosophy}

Students usually tend to confuse these research methodological terms. The research design describes the approaches through which data will be interpreted. The major types of the research designs are exploratory, descriptive and explanatory or experimental designs (Kumar, 2011). The exploratory design is applied when the problem is not known while the descriptive design is done to describe the situation and explanatory or experimental design gives the chance of explaining the relationship between the variables. When the descriptive design offers an opportunity to explain the relationship between variables, it is called 
descriptive correlational. However, descriptive correlational design can't explain fully the cause-effect relationship between variables as in experimental design (Stangor, 2011). There are also the types of the research designs which explain if the study done at once (cross sectional design) or is repeated (longitudinal design) or if the study concentrates only at a particular location (case study design). Therefore, a student may use multiple of the study designs. The tendency of most students is to use the descriptive design without arguing its strengths, weaknesses and justification on how the weaknesses have been mitigated. Students should avoid using a particular design just because it is very simple to use.

When it comes to research approach, strategy and philosophy also students have a tendency to confuse these concepts. However, According to Sudeshna and Datt (2016), research approach is a plan and procedure that guides data collection, analysis, interpretation, and reasoning. The approaches for data collection are qualitative, quantitative or mixed while the approaches for data analysis or reasoning are inductive or deductive. The other major problem for students is failure to ascertain when and why the mixed research design is used. Also students fail to disclose the types of the mixed research design whether are sequential/concurrent or multiphase or iterative mixed methods designs and fail to specify their categories. According to PHWT (2018), the sequential mixed research designs are categorized into exploratory and explanatory mixed method designs while the concurrent mixed designs are classified into convergent and embedded or nested mixed method designs.

Saunders et al. (2012) assert that selection of an appropriate research strategy helps a researcher to answer the research questions in a systematic/logical way. Therefore, most researchers use the research approach and strategy synonymously. The research philosophy is the assumptions from groups of previous researchers about how the good research should be conducted. Therefore, the research philosophy expresses the assumptions about the way the researcher views the world. The assumptions relates with human knowledge and about the nature of the realities and shapes the way the researcher understands the research questions and ultimately they will determine the methods for interpreting the findings (Saunders et al., 2012). In this context, students may choose to adopt either positivism, interpretivism, pragmatism or any type of philosophy, provided that they give the justifiable reasons for choosing a particular philosophy.

\subsubsection{Variables and Measurements}

While a variable is anything which can vary (Lunsford, 1993), the experience shows that most students fail to present properly the section of the variables and measurement. Greenstein (2006) by citing Kaplan (1964) proposed the three ways things that can be measured. These include direct observation, indirect observation and using the construct creation for the things which can't be observed directly or indirectly. Moreover, it is important for the researcher to include operationalization of the variables and this translates the abstractions into tangible measurements.

According to Greenstein (2006), the variables can be measured into four levels. Firstly; by using nominal level where order consideration is not important. This can be used in classifying, for example the marital status of the respondents where any point in the likert 
scale can be used to indicate the marital status of the respondents. Secondly, by using the ordinal level where order consideration is important. Example of this is the level of education where the researcher can't categorize starting the middle point. Thirdly, by using the interval scale, where there are intervals between one scale and the other and the decimal point is not allowed. Fourthly, ratio scale which combines nominal, ordinal and interval scales and in this level of the scales, decimal points are allowed.

In using the four level of variables' measurement, the variables can be explained by using data analysis methods such as descriptive quantitative statistics (frequency, mean, mode, median, standard deviation, range) or inferential statistics such as chi-square, correlation, regression or any other inferential methods. Moreover, after categorizing data into the four levels, variables can be measured by using the International standard scales of measurements. For example, the company performance may be measured by using the financial and non-financial measures such as profitability, growth, customer satisfaction, employee satisfaction, social performance, and environmental performance (Santos \& Brito, 2012).

\subsubsection{Data Analysis, Results and Interpretation}

As indicated in the previous sections, most students use descriptive statistics but only few present the strengths and weaknesses of this method. The biggest problem of the descriptive statistics is its failure in explaining the causative nature between variables (IPFS, 2016). Hence, the results from the descriptive statistics have low degree of validity. Another big problem for students is to present data without discussing them so that readers of the research report may understand the meaning of the data. Discussion of data should explain the results implications and the students should compare and contrast the results with previous studies (Hess, 2004). In some types of the studies (mostly in the science based studies), the chapter of data presentation and discussion is separated while in social science it is usually combined. This however, will depend on the instructions of the journal article or the university reporting format. Nevertheless, combing results and discussion requires enough skills and care, because it poses chances of unnecessary repetitions.

\subsubsection{Conclusion and Recommendations}

This is always the last chapter of the study. The chapter of conclusion and recommendations usually covers the summary of findings, conclusion, recommendations, the study implications, contribution, and the direction for the future studies. The major problem for the students is to write this chapter without adhering to the flow of writing. For instance, the students may start conclusion without first summarizing the findings. Another problem is to present overcrowded information in the conclusion section. San Francisco Edit (2019) emphasizes that the conclusion should be written in a summarized form. The author recommends that it should not exceed two paragraphs or more than a half of page and if necessary, it should not exceed one page. In fact, students should be aware that the conclusion section is the summary of the "summary of the findings." The conclusion of the study is normally preceded by the recommendations of the study.

The major weakness for the students while writing recommendations is to recommend some 
of the issues which a are not coming from their studies. Principally, the recommendations should emanate from the findings of the study (Hess, 2004). Another weakness is that the students forget to write the contribution of the study to theories which have been outlined in the chapter of the literature review. The recommendations should also cover the theoretical, practical and policy implications in a narrative way. The students also should present the limitations of the study. These are the weaknesses of a particular study which include small sample size, little geographical coverage, weaknesses in data analysis methods and other challenges which will guide readers to use the findings of the study cautiously. The students also should state the direction of the future studies. These may be the gaps which have been revealed by the researcher during data collection but they were beyond the scope of the study. Hence, the students should direct other scholars to search more details of these variables in the future studies.

\subsection{Other Challenges Hindering Students to Accomplish Timely Their Theses and Dissertations}

Apart from students' inadequate writing skills, there are other challenges which hinder students' theses or dissertation timely completion at the OUT. Some of the reasons are presented below:

\subsubsection{Insufficient Research Orientation}

Mostly in Tanzania research is not taught from the primary schools. Since research is a systematic knowledge, it is difficult for the students to learn it in a short period of time say two weeks, one month and even two months and understand the research concepts and processes. It should be noted that, in Tanzania some of the postgraduate students learn research while they are at university, when they are pursuing their bachelor degrees and even some of the students learn research when they are at a master level. In this way, it is difficult for them to understand the research concepts for a short period of time. For example, and surprisingly, when I was training our master students the research methodology course and particularly when sharing their understanding of a research gap one student revealed that it was from that day she understood what a research gap mean (the gap of what has been researched and what has not been researched), because previously she thought that a research gap, is just leaving a gap between paragraphs when writing the proposal! Therefore, because of these inadequate research skills, students don't know what to write. Moreover, it should be noted that, despite of the establishment of many soft skills research courses which geared towards improving the research writing skills to students at OUT; many students don't consider this as an opportunity for improving their research writing skills. Nenty (2009) affirmed that lack of research orientation caused low motivation for postgraduate students in Botswana to carry out their researches as planned. This hindered their choice of research problem and lowered the understanding on the importance of research skills for their future works. 


\subsubsection{Lack of Reading Culture}

In this era of information and communication technology, at least all the information which describes how to conduct a credible research is available on the Internet. However, despite such opportunity, students fail to write the research concepts correctly. This is probably caused by lack the reading culture for some of the OUT's students. There is joke in Tanzania that, "if you want to hide gold, put it in the middle of the book." Therefore, because of lack of reading culture, students usually give many excuses on why they have not presented correctly the research concepts such as being too busy, they were sick, etc. Gordon and Lu (2008) found that low achievers students hated reading at the State University of New Jersey because they struggled to read. The strategy of reading the popular titles novels was devised to promote the reading attitude for these students.

\subsubsection{Lack of Facilitation Methods' Integration for Research Course Trainers}

Most of instructors use only the lecturing method when training research courses to postgraduate students where power point presentation is used in delivering the materials. The author is in the view that, using this method alone is not suitable for aged students because power point presentations make students not to comprehend well the research concepts. The author recommends that the combination of both theoretical and practical training methods could foster the understanding of the research concepts to students. To cement this point, Wade (1996) found that the factors that contributed to training effectiveness were experience, training, personality, attitude and organizational support. These factors may also be used to promote more students' research course understanding at the OUT.

\subsubsection{Lack of Awareness on Students-Supervisors Responsibilities}

Squarely, students should understand that they are the owner of the research they are making. Therefore in terms of portions, the percentage of responsibilities between the supervisors and students; students may have the role of more than $70 \%$ of making their studies successful. However, some of the students do not understand this truth. They think that only a supervisor can determine their studies' accomplishment. Sometimes lack of knowing the supervisor-student responsibilities is the cause of the conflicts between the students and the supervisors and this usually delay the accomplishment of research projects because the students do not spare enough time to read on how to write the good research reports (Blum \& Preiss, 2005).

\subsubsection{Lack of Research Completion Strategy}

Based on the way the students write their theses or dissertations, the author perceives that students do not have strategies which could help them accomplish their studies within the prescribed standard time. Some of these strategies may include reading the research procedures, reading the previous related research proposals and reports, consultation with colleagues who have already completed their theses or dissertations timely, dealing with supervisors' comments and other things. Wilfrid Laurier University (2009) has proposed various strategies which promote students' timely completion of their researches projects. One of the strategies is for students to set the due dates for their research completion. This 
strategy promotes the time management and helps the students to track the dissertation and theses completion progress and time.

\subsubsection{Low Level of English Language Proficiency}

English language proficiency is the problem for Tanzanian students because while the research writing language is English; the mother tongue is not English. For most Tanzanians, English is the third language (The first language is vernacular, second Kiswahili and third English language). Therefore, most students have English writing problems and this hinders their effective writing of the good research proposals and reports. Due to language barrier, students fail to present and argue their research concepts and ideas. Some of the students even fail to construct good sentences when writing their research proposal and reports. Due to poor English language proficiency, some supervisors withdraw from supervising students because they do not understand what students write. It happens in some cases that students fail to link the concepts in the sentences and paragraphs. Furthermore, due to low English language proficiency, students fail to write the original research articles and reports. Hence, students are tempted to copy and paste materials from the Internet and if the university tests the plagiarism level, students are prohibited to graduate unless they reduce the plagiarism to the required tolerance levels; and this sometimes becomes a tedious task to students. Low level of English Language proficiency has been reported as a problem for students who write their reports by Iftanti (2016), Fareed et al. (2016), Alfaki (2015), and Shang (2013), just to mention a few.

\subsubsection{Lack of Funds and Health Problems}

Few students face the challenges of lack of funds which hinder carrying out their research activities and payment of the tuition fees. Some students also fail to complete on time their research projects due to health related issues.

\section{Contribution of the Study to the Social Cognitive Theory and Behavioural Theory}

This article contribute to both social cognitive theory and cognitive-behavioral theory in the following ways: students should understand that research skills are gained through the practices of reading and writing frequently and they should take initiative to understand both the writing language and familiarize themselves with the research concepts and processes. Therefore, students should diligently study on how to conduct a good credible research and if they succeed, they will be imitated by others. In addition students should not be depressed by the various challenges they face when making their master and $\mathrm{PhD}$ research projects such as unfriendly supervisors, low language proficiency, inadequate experiences on research, etc but they should be creative to devise strategies to overcome these challenges to facilitate their researches completion. The position of this paper implies that the social cognitive theory and cognitive-behavioral theory do not focus on variables such as creativity, diligence and endurance. The author is in the opinion that these variables can also promote learning.

\section{Conclusion and Recommendations of the Paper}

The analysis shows that both writing skills and other outlined challenges impede the 
postgraduate students to complete their theses and dissertations on time at the OUT. Moreover, the paper shows that the social cognitive theory and behavioural theory as a lens are related with strategies which may be used by students to improve their research writing skills and may be used to overcome other challenges which hinder timely completion of theses and dissertation at the OUT. In order to improve the research writing skills and overcome other challenges for postgraduate students at the OUT and other higher learning institutions in Tanzania, this paper recommends the following; the research skills should be trained since primary schools. Furthermore, attending the soft skills research courses should be mandatory for all students before their proposals' presentation and during the research report writing. In addition, the reading culture among Tanzanians students should be promoted. The research instructors should be trained on adult trainer facilitation courses and they should combine both theoretical and practical methods during training to enhance the students' understanding of the research concepts and processes. Likewise, the students-supervisors responsibilities should be defined at the beginning of the research and the students should devise strategies that will help them accomplish their research timely. Finally, students should increase the English proficiency by reading English articles and reports, attend the English courses and communicate using English language regularly.

\section{References}

Adas, D., \& Bakir, A. (2013). Writing difficulties and new solutions: blended learning as an approach to improve writing abilities. International Journal of Humanities and Social Science, 3(9), 254- 266.

Akers, H. (2018). What is cognitive theory? Retrieved September 29, 2018, from https://www.wisegeek.com/what-is-cognitive-theory.htm

Alfaki, I. M. (2015). University students' English writing problems: diagnosis and remedy. International Journal of English Language Teaching, 3(3), 40-52.

Bandura, A. (1977). Self-efficacy: Toward a unifying theory of behavioral change. Psychological Review, 84(2), 191-215.

Bandura, A. (1986). Social foundations of thought and action: a social cognitive theory. Englewood Cliffs, NJ: Prentice-Hall. https://doi.org/10.1037/0033-295X.84.2.191

Bandura, A. (2001). Social Cognitive Theory of Mass Communication. Media Psychology, 3 (3), 265-299. https://doi.org/10.1207/S1532785XMEP0303_03

Bandura, A. (2011). The Social and Policy Impact of Social Cognitive Theory. In M. Mark, S. Donaldson \& B. Campbell (Eds.), Social Psychology and Evaluation (pp. 33-70). New York, NY: Guilford Press.

Bavdekar, S. B. (2015). Writing introduction: laying the foundations of a research paper. Journal of the Association of Physicians of India, 63(July 2015), 44-46.

Beck, A. T. (1976). Cognitive therapy and the emotional disorders. New York, NY: Meridian.

Blicblau, A. S., McManus, K. J., \& Prince, A. (2009). Developing writing skills for graduate 
NESBC students. The Reading Matrix, 9(2), 198-210.

Blum, K. D., \& Preiss, A. E. (2005). Strategies to win: six-steps for creating problem statements in doctoral research. Journal of College Teaching \& Learning, 2(11), 47-52.

Chokwe, J. M. (2013). Factors impacting academic writing skills of English second language students. Mediterranean Journal of Social Sciences, 4(14), 377-383. https://doi.org/10.5901/mjss.2013.v4n14p377

Fareed, M., Ashraf, A., \& Bilal, M. (2016). ESL learners' writing skills: problems, factors and suggestions. Journal of Education and Social Sciences, 4(2-1), 81-92. https://doi.org/10.20547/jess0421604201

Farooq, R. (2017). A framework for identifying research gap in social sciences: evidence from the Past. Retrieved March 10, 2019, from https://www.researchgate.net/publication/325285640_A_Framework_for_Identifying_R esearch_Gap_in_Social_Sciences_Evidence_from_the_Past

Farrah, M. (2012). The Impact of Peer Feedback on Improving the Writing skills among Hebron University Students. An - Najah Univ. J. Res. (Humanities), 26(1), 180-210.

Farrugia, P., Petrisor, B. A., Farrokhyar, F., \& Bhandari, M. (2010). Research questions, hypotheses and objectives. J can chir, 53(4), 278-281.

Fischler, A. (2019). From problem statement to research questions. Retrieved March 10, 2019, from

https://education.nova.edu/Resources/uploads/app/35/files/arc_doc/from_problem_state ment_to_research_questions.pdf

Gordon, C., \& Lu, Y. (2008). I hate to read-or do I? Low achievers and their reading. Research Journal of the American Association of School Librarians, 11(2008), 1-15.

Greenstein. (2006). 5-How do we measure concepts? Retrieved March 10, 2019, from https://us.sagepub.com/sites/default/files/upm-binaries/11208_Chapter_5.pdf

Hess, D. (2004). How to write an effective discussion. Respiratory Care, 49(10), 1238-1241.

Ho, P. V. P., Ngoc, P., \& Duong, T. (2015). Common Errors in Writing Journals of the English-Major Students at HCMC Open University. Journal of Science Ho Chi Minh City Open University, 2(14), 54-61.

Holt, E. B., \& Brown, H. C. (1931). Animal drive and the learning process, an essay toward radical empiricism. New York: H. Holt and Co.

Iftanti, E. (2016). Improving students' writing skills through writing journal articles: 1 Lingua Scientie, 8(1), 1-22. https://doi.org/10.21274/1s.2016.8.1.1-22

IPFS. (2016). Descriptive research. Retrieved July 29, 2018, from https://ipfs.io/ipfs/QmXoypizjW3WknFiJnKLwHCnL72vedxjQkDDP1mXWo6uco/wiki /Descriptive_research.html 
Itua, M., Coffey, M., Merryweather, D., Norton, L., \& Foxcroft, A. (2014). Exploring barriers and solutions to academic writing: perspectives from students, higher education and further education tutors. Journal of Further and Higher Education, 38(3), 305-326. https://doi.org/10.1080/0309877X.2012.726966

Jilcha, K. (2017). Introduction vs Background. Retrieved March 12, 2019, from https://www.researchgate.net/post/What_is_the_difference_between_introduction_and_b ackground_in_research_proposal_and_statement_of_problem_and_rationale_of_the_stu dy

Kaplan, A. (1964). The conduct of inquiry: Methodology for behavioral science. San Francisco: Chandler.

Kellogg, R. T. (2008). Improving the writing skills of college students. Psychonomic Bulletin \& Review (Production Number RCE709). Retrieved July 24, 2018, from http://www.writing.ucsb.edu/wrconf08/Pdf_Articles/Kellogg_\&_Raulerson_Article.pdf

Kumar, R. (2011). Research methodology: a step-by-step guide for beginners (3rd ed.). SAGE, New Delhi.

Lin, M. H., Li, J., Hung, P. Y., \& Huang, H. (2014). Blogging a journal: changing students' writing skills and perceptions. ELT Journal, 68(4-1), 422-431. https://doi.org/10.1093/elt/ccu032

Lumpkin, A. (2015). Students' enhancing undergraduate research and writing. International Journal of Teaching and Learning in Higher Education, 27(1), 130-142.

Lunsford, B. R. (1993). Methodology: variables and levels of measurement. Journal of Prosthetics and Orthotics, 5(4), 421-424. https://doi.org/10.1097/00008526-199310000-00006

MacArthur, C. A. (2009). Reflections on research on writing and technology for struggling writers. Learning Disabilities Research \& Practice, 24(2), 93-103. https://doi.org/10.1111/j.1540-5826.2009.00283.x

McNaught, K., \& Benson, S. (2015). Increasing student performance by changing the assessment practices within an academic writing unit in an enabling Program. The International Journal of the First Year in Higher Education, 6(1), 73-87. https://doi.org/10.5204/intjfyhe.v6i1.249

Miller, J. (2014). Building academic literacy and research skills by contributing to Wikipedia: A case study at an Australian university. Journal of Academic Language \& Learning, $8(2), \mathrm{A}-72-\mathrm{A}-86$.

Mouza, M. (2018). What is Theory. Retrieved March 13, 2019, from https://www.researchgate.net/publication/327079505_WHAT_IS_THEORY

Nakano, D., \& Muniz Jr., J. (2018). Writing the literature review for an empirical paper. Production, 28, e20170086. https://doi.org/10.1590/0103-6513.20170086 
Nenty, H. J. (2009. Research orientation and research-related behaviour of graduate education students. J Soc Sci, 19(1), 9-17

Nik, Y. A., Bt. Sani, B., Noor, M. B., Chik, W., Jusoff, K., \& Bin Hasbollah, S. R. (2010). The writing performance of undergraduates in the University of Technology Mara, Terengganu, Malaysia. Journal of Languages and Culture, 1(1), 8-14.

O’Neill, K. S., \& Gravois, R. (2017). Using a focus on revision to improve students' writing skills. Journal of Instructional Pedagogies, 19, 1-12.

OUT Graduation Booklet. (2018). The Open University of Tanzania, thirty-four congregation for the conferment and presentation of degree, diploma and certification at OUT Simiyu centre on 22nd February 2018. The Open University of Tanzania.

Pesik, R. (2010). Improving student's performance and writing skills by using photography, autophotography and music. Master of Education Thesis, University of Victoria.

Phillips, E. M., \& Pugh, D. S. (2005). How to Get a PhD: A handbook for students and their supervisors (4th ed.). England: Open University Press.

Public Health Workforce Training. (PHWT, 2018). Five main types of mixed methods design. Retrieved October 3, 2018, from http://raining.lowernysphtc.org/introduction-to-mixed-methods-research/five-mixed-me thods-design/

Sajid, M., \& Siddiqui, J. A. (2015). Lack of academic writing skills in English language at higher education level in Pakistan: Causes, effects and remedies. International Journal of Language and Linguistics, 2(4), 174-186.

San Francisco Edit. (2019). Eleven steps to writing an effective conclusion. Retrieved from https://www.vetmeduni.ac.at/fileadmin/v/parasitologie/Downloads_Dissertationen_Dipl omarbeiten/Leitf\%C3\%A4den_San_Francisco_Edit/conclusion.pdf

Santos, J. B., \& Brito, L. A. L. (2012). Toward a Subjective measurement model for firm performance. Brazilian Administration Review, 9(6), 95-117. https://doi.org/10.1590/S1807-76922012000500007

Saunders, M., Lewis, P., \& Thornhill, A. (2012). Reserach methods for business students. Harlow: Pearson Education Limited.

Sersen, W. J. (2011). Improving writing skills of Thai EFL students by recognition of and compensation for factors of L1 to L2. US-China Education Review, A3, 339-345. Earlier title: US-China Education Review Negative Transfer.

Shang, H. (2013). Factors associated with English as a foreign language university students' writing anxiety. International Journal of English Language Teaching, 1(1), 1-12.

Shay, J. N. (2015). How to write 'introduction' in scientific journal article. Journal of Patan Academy of Health Sciences, 2(1), 1-2. https://doi.org/10.3126/jpahs.v2i1.20331 
Smith, M. E., Theorpe, R., \& Jackson, P. R. (2008). Management research (3rd ed.). London, UK: SAGE Publication.

Stangor, C. (2011). Research methods for the behavioral sciences (4th ed.). Mountain View, $\mathrm{CA}$ : Cengage.

Sudeshna \& Datt, S. (2016). Importance of research approach in a research. Retrieved July 29 , 2018 , from https://www.projectguru.in/publications/selecting-research-approach-business-studies/

Sulisworo, D., Rahayu, T., \& Akhsan, R. N. (2016). The students' academic writing skill after implementing blended learning using facebook. Information Technologies and Learning Tools, 56(6), 176-191. https://doi.org/10.33407/itlt.v56i6.1477

Tan, E. B. (2007). Research experiences of undergraduate students at a Comprehensive University. International Journal of Teaching and Learning in Higher Education, 19(3), 205-215.

The Open University of Tanzania. (OUT, 2018). Facts and figures of OUT in 2018.

Tichapondwa, S. M. (2013). Preparing your dissertation at a distance (ed). A research guide Virtual University for Small States of the Common wealth-(VUSSC).

Vijayakumar, J. K., \& Vijayakumar, M. (2007). Importance of doctoral theses and its access: A literature analysis. TGJ, 3(2), 67-75.

Wade, M. I. (1996). Factors for effective facilitator training evaluation. Master of Science Thesis. Air force Institute of Technology.

Whitaker, A. (2009). A step-by-step guide to writing academic papers. Retrieved August 14, 2018, from http://www.vsm.sk/Curriculum/academicsupport/academicwritingguide.pdf

Wikipedia. (2018). Social cognitive theory. Retrieved September 29, 2018, from https://en.wikipedia.org/wiki/Social_cognitive_theory

Wilfrid Laurier University. (2009). Strategies for researchers. Retrieved from https://web.wlu.ca/learning_resources/pdfs/Research_Strategies.pdf

\section{Copyrights}

Copyright for this article is retained by the author(s), with first publication rights granted to the journal.

This is an open-access article distributed under the terms and conditions of the Creative Commons Attribution license (http://creativecommons.org/licenses/by/4.0/). 